\title{
Aktivitas Antioksidan dan Toksisitas Akut Ekstrak Etanol Buah, Daun, Batang dan Rimpang Tanaman Wualae (Etlingera elatior (Jack) R.M. Smith)
}

\author{
Mesi Leorita, Sandra Aulia Mardikasari, Wahyuni, Muhammad Hajrul Malaka, Ari Sartinah, \\ Sahidin*
}

Fakultas Farmasi Universitas Halu Oleo, Kampus Hijau Bumi Tridharma Anduonohu Kendari 93232

E-mail: sahidin02@uho.ac.id

\begin{abstract}
Abstrak
Wualae (Etlingera elatior (Jack) R.M Smith) merupakan salah satu jenis tanaman dari famili zingiberaceae yang digunakan masyarakat Suku Tolaki di Provinsi Sulawesi Tenggara sebagai bumbu masak dan obat secara empiris. Wualae diduga memiliki potensi antioksidan karena mengandung flavonoid. Penelitian ini bertujuan untuk mengetahui potensi antioksidan ekstrak etanol buah, daun, batang dan rimpang wualae terhadap radikal bebas 1,1-difenil-2-pikrihidrazil (DPPH) dan toksisitas akut terhadap larva Artemia salina Leach menggunakan metode BSLT. Ekstrak diperoleh dengan metode maserasi menggunakan pelarut etanol $96 \%$ selama $3 \times 24$ jam dan dipekatkan pada suhu $60^{\circ} \mathrm{C}$. Hasil uji aktivitas antioksidan ekstrak etanol buah, daun, batang dan rimpang Wualae, diperoleh hasil bahwa semua bagian tanaman Wualae memiliki potensi sebagai antioksidan dengan afektifitas masuk dalam katagori kuat. Nilai IC50 yang paling baik terdapat pada bagian batang $(52,345 \mathrm{mg} / \mathrm{L})$, selanjutnya pada rimpang $(58,638 \mathrm{mg} / \mathrm{L})$, pada buah $72,518 \mathrm{mg} / \mathrm{L}$ dan pada daun $99,890 \mathrm{mg} / \mathrm{L}$. Hasil uji toksisitas akut menunjukkan bahwa buah, daun, batang dan rimpang Wualae bersifat sedikit toksik (slightly toxic) dengan nilai LC 50 masing-masing sebesar $1302.31 \mu \mathrm{g} / \mathrm{mL}, 1162.84 \mu \mathrm{g} / \mathrm{mL}, 1174.52$ $\mu \mathrm{g} / \mathrm{mL}$ dan $1074.72 \mu \mathrm{g} / \mathrm{mL}$.
\end{abstract}

Kata kunci: wualae, Etlingera, antioksidan, toksisitas, obat tradisional, Sulawesi Tenggara

\section{Pendahuluan}

Peningkatan prevalensi penyakit degeneratif di Indonesia cukup pesat, yang terdiri dari jantung koroner, gagal jantung, stroke, gagal ginjal kronis, dan diabetes militus [1]. Salah satu pemicu terjadinya penyakit degeneratif adalah radikal bebas yang disebabkan oleh atom atau molekul yang bersifat reaktif. Molekul radikal dengan kereaktifan yang tinggi dapat menyebabkan sebuah reaksi sehingga membentuk senyawa abnormal dan memulai reaksi berantai yang dapat merusak sel-sel penting dalam tubuh [2].

Reaksi radikal bebas dapat diatasi dengan penggunaan antioksidan yang melindungi sel dari kerusakan dengan cara menetralkan molekul radikal bebas [3]. Saat ini perhatian terhadap antioksidan alami dan pemanfaatannya dalam menjaga kesehatan semakin tinggi. Tanaman merupakan sumber antioksidan alami yang sangat potensial. Antioksidan alami terdapat pada seluruh bagian tanaman berupa karotenoid, vitamin, flavonoid, dan fenol [4]. Tanaman Wualae atau dalam bahasa Indonesia disebut dengan kecombrang (Etlingera elatior (Jack) R.M Smith) merupakan salah satu jenis tanaman dari famili zingiberaceae yang digunakan masyarakat Suku Tolaki di Provinsi Sulawesi Tenggara sebagai bumbu masak dan obat secara empiris. Hasil penelitian Maimulyanti \& Prihadi (2015) diketahui bunga wualae (kecombrang) mengandung senyawa tanin, flavonoid, saponin dan steroid, serta hasil uji aktivitas antioksidan dengan metode DPPH menunjukkan bahwa ekstrak metanol dan etilasetat bunga Wualae memiliki nilai IC50 berturut-turut 21,14 dan 68,24 $\mu \mathrm{g} / \mathrm{ml}$ [5]. Penelitian pada semua bagian tanaman Wualae yang tumbuh di Sulawesi Tenggara sebagai antioksidan belum pernah dilakukan.

Bentuk pertanggungjawaban ilmiah penggunaan tanaman sebagai obat, selain dilakukan uji aktivitas perlu dilakukan juga uji toksisitas. Uji toksisitas sangat penting dilakukan sebagai langkah awal parameter keamanan obat sebelum menjadi produk obat yang dapat digunakan pada manusia. Hal ini dikarenakan setiap bahan obat memiliki potensi bersifat toksik tergantung takarannya dalam tubuh.

Tujuan dari penelitian ini adalah untuk mengetahui aktivitas antioksidan terhadap radikal bebas DPPH dan toksisitas akut terhadap larva udang (Artemia salina Leach) menggunakan metode BSLT dari ekstrak etanol buah, daun, batang dan rimpang Wualae (Etlingera elatior (Jack) R.M Smith).

\section{Metode}

\subsection{Preparasi dan Ekstraksi}

Sampel (buah, daun, batang, dan rimpang wualae) masing-masing dibersihkan, dicuci setelah itu dipotong- 
potong kecil secara terpisah. Tiap sampel dikeringkan kemudian dihaluskan menggunakan pencacah elektrik. Tiap serbuk sampel dimaserasi menggunakan pelarut etanol selama $3 \times 24$ jam. Filtrat dari tiap sampel yang diperoleh dipekatkan menggunakan evaporator hingga diperoleh ekstrak kental.

\subsection{Identifikasi dan karakterisasi ekstrak}

Identifikasi senyawa yang terkandung di dalam ekstrak daun, bunga, batang dan rimpang Wualae menggunakan skrining fitokimia, yang terdiri atas pemeriksaan alkaloid, flavonoid, saponin, tanin, dan steroid. Karakterisasi ekstrak meliputi penetapan kadar air, kadar abu, kadar sari larut etanol dan kadar sari larut air.

\subsection{Uji Aktivitas Antioksidan dengan Metode DPPH}

Aktivitas antioksidan dinyatakan dengan nilai Inhibitor Concentration $50\left(\mathrm{IC}_{50}\right)$ dari masing masing sampel. Sampel direaksikan dengan larutan DPPH kemudian diukur menggunakan spektrofotometer UV-Vis pada panjang gelombang $517 \mathrm{~nm}$.

\subsection{Uji Sitotoksik Akut}

Uji sitotoksik akut dilakukan terhadap larva udang Artemia salina Leach yang berumur 48 jam dengan metode BSLT. Larutan ekstrak etanol buah, daun, batang dan rimpang Wualae masing-masing dibuat menjadi 5 konsentrasi, yaitu konsentrasi 500 ppm, 250 ppm, 125 ppm, $62,5 \mathrm{ppm}$ dan 31,25 ppm. Kontrol negatif menggunakan campuran etanol, DMSO, dan air laut. Dilakukan replikasi tiga kali dengan jumlah total larva udang dalam tiap konsentrasi sebanyak 180 ekor. Pengujian dilakukan selama dua puluh empat jam, kemudian dihitung nilai $\mathrm{LC}_{50}$.

\section{Hasil dan Pembahasan}

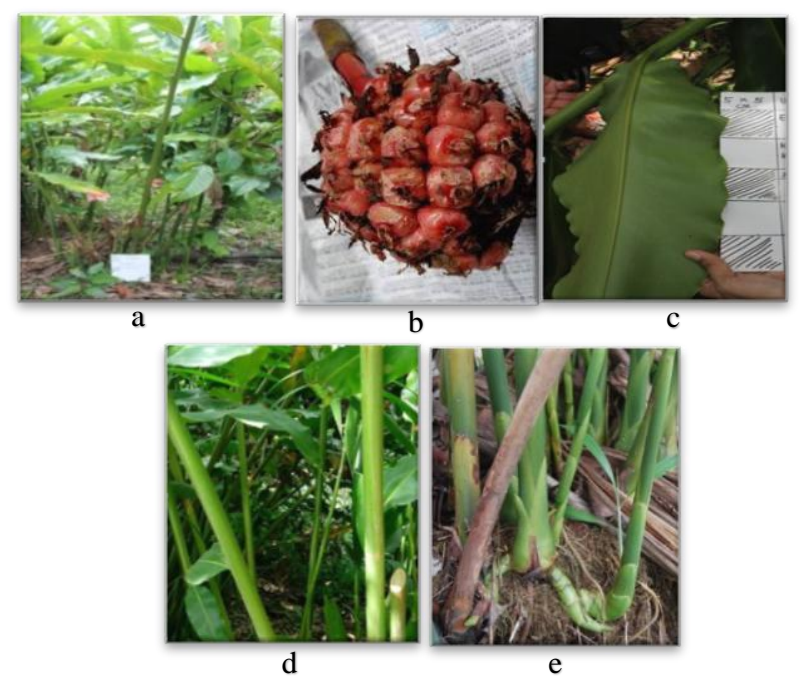

Gambar 1. Tanaman wualae (a); buah wualae (b); daun (c); batang (d); dan rimpang (e)
Sampel yang digunakan pada penelitian ini diperoleh dari Kelurahan Sambeani, Kecamatan Abuki, Kabupaten Konawe Selatan Provinsi Sulawesi Tenggara Masing masing bagian tanaman dibuat serbuk simplisia, dimaserasi lalu dipekatkan sehingga menjadi ekstrak kental. Diperoleh nilai rendemen buah sebesar $5,1 \%$, nilai rendemen daun $4,4 \%$, nilai rendemen rimpang $3,5 \%$ dan nilai rendemen batang $1,5 \%$. Tujuan dari perhitungan nilai rendemen adalah untuk mengetahui persentase perolehan hasil ekstraksi sehingga nantinya dapat diketahui jumlah simplisia yang dibutuhkan untuk membuat sejumlah ekstrak kental yang dibutuhkan.

Hasil skrining fitokimia menunjukkan bahwa ekstak kental daun, buah, rimbang dan akar tanaman Wualae mengandung flavonoid (Tabel 1). Flavonoid merupakan senyawa polifenol mempunyai kemampuan untuk menyumbangkan atom hidrogen kepada senyawa radikal bebas [6]. Hal ini memperkuat dugaan semua bagian tanaman Wualae memiliki potensi sebagai antioksidan.

Tabel 1. Hasil skrining fitokimia ekstrak etanol bagian tanaman wualae

\begin{tabular}{lccccc}
\hline \multirow{2}{*}{ Sampel } & \multicolumn{5}{c}{ Metabolit sekunder } \\
\cline { 2 - 6 } & Alkaloid & Flavonoid & Tanin & Saponin & Triterpenoid \\
\hline Buah & + & + & + & - & + \\
Daun & + & + & + & + & - \\
Batang & + & + & + & + & - \\
Rimpang & + & + & + & + & + \\
\hline
\end{tabular}

Keterangan: (+) mengandung senyawa yang diuji; (-) tidak mengandung senyawa yang diuji

Semua ekstrak kental dari bagian tanaman Wualae memenuhi syarat karakteristik non spesifik, yaitu memiliki kadar air $<10 \%$ dan kadar abu $<7 \%$ Kadar air yang rendah membuat kapang dan jamur tidak mudah tumbuh, serta kadar abu berada di bawah ambang batas berarti ekstrak tidak tercemar logam.

Tabel 1. Hasil karakterisasi ekstrak etanol bagian tanaman wualae

\begin{tabular}{lllll}
\hline \multirow{2}{*}{ Jenis Karakterisasi } & \multicolumn{4}{c}{ Hasil } \\
\cline { 2 - 5 } \begin{tabular}{l} 
Organoleptis \\
\multicolumn{1}{c}{ Bentuk }
\end{tabular} & Daun & Batang & Rimpang & Buah \\
Warna & Hijau & Hijau & Coklat & Merah \\
Tua & Khas & Khas & Khas & Khas \\
Kadar Air & $9,33 \%$ & $5,57 \%$ & $1,87 \%$ & $5,26 \%$ \\
Kadar Abu & $0,25 \%$ & $0,41 \%$ & $3,15 \%$ & $6,28 \%$ \\
Kadar Sari Larut & $47,23 \%$ & $48,78 \%$ & $40,65 \%$ & $61,07 \%$ \\
Etanol & $23,68 \%$ & $23,19 \%$ & $36,62 \%$ & $41,65 \%$ \\
Kadar Sari Larut Air & & & & Kental \\
\hline
\end{tabular}

Uji aktivitas antioksidan rimpang, batang, daun, buah Wualae dilakukan secara in vitro dengan metode kuantitatif menggunakan DPPH sebagai radikal bebas. Vitamin C (asam askorbat) dipilih sebagai pembanding, dikarenakan vitamin $\mathrm{C}$ termasuk obat bebas, memiliki harga yang murah, terjangkau oleh masyarakat, dan memiliki khasiat antioksidan yang kuat.

Prinsip pengukuran aktivitas antioksidan berdasarkan adanya perubahan intensitas warna ungu larutan DPPH menjadi warna kuning. Perubahan intensitas warna ini disebabkan adanya peredaman radikal bebas, yakni 
elektron tidak berpasangan pada molekul DPPH menjadi berpasangan dengan atom hidrogen yang dilepaskan oleh molekul senyawa sampel sehingga terbentuk senyawa difenil pikrilhidrazil yang menyebabkan terjadinya perubahan warna DPPH. Perubahan warna ini akan memberikan perubahan absorbansi pada panjang gelombang maksimum DPPH menggunakan spektrofotometri UV-Vis sehingga diketahui nilai aktivitas peredaman radikal bebas yang dinyatakan dengan nilai Inhibitory Concentration $\left(\mathrm{IC}_{50}\right.$ ) [7]. Pada penelitian ini pengukuran dilakukan dengan panjang gelombang $517 \mathrm{~nm}$, karena panjang gelombang ini merupakan panjang gelombang maksimum yang memberikan serapan kuat.

Hasil uji antioksidan pada semua bagian tanaman Wualae menunjukkan bahwa peredaman radikal DPPH meningkat seiring dengan meningkatnya konsentrasi larutan, yang ditandai dengan semakin besarnya nilai persen penghambatan. Nilai hasil uji antioksidan dapat dilihat pada Tabel 3. Berdasarkan katagori Blois [8], aktivitas antioksidan pada ekstrak etanol setiap bagian tanaman Wualae termasuk katagori kuat dengan nilai $\mathrm{IC}_{50}$ terbaik pada batang sebesar $52,345 \mathrm{mg} / \mathrm{L}$, lalu rimpang dengan $\mathrm{IC}_{50} 58,638 \mathrm{mg} / \mathrm{L}$, selanjutnya $\mathrm{IC}_{50}$ buah 72,518 $\mathrm{mg} / \mathrm{L}$, dan $\mathrm{IC}_{50}$ pada daun 99,890 mg/L. Aktivitas antioksidan setiap bagian tanamam Wualae masih lebih rendah dibandingkan dengan vitamin $\mathrm{C}$ yang memiliki aktivitas antioksidan yang sangat kuat dengan nilai $\mathrm{IC}_{50}$ sebesar 3,787 mg/L.

Tabel 3. Aktifitas antioksidan bagian tanaman wualae dan vitamin C

\begin{tabular}{|c|c|c|c|}
\hline No. & Sampel & Persamaan Grafik* & $\begin{array}{c}\text { Nilai IC } \text { I }_{50} \\
(\mathrm{mg} / \mathrm{L})\end{array}$ \\
\hline 1. & Buah & $\begin{array}{l}y=0,166 x+37,96 \\
R^{2}=0,998\end{array}$ & 72,518 \\
\hline 2 & Daun & $\begin{array}{l}y=0,264 x+23,57 \\
R^{2}=0,981\end{array}$ & 99,890 \\
\hline 3 & Batang & $\begin{array}{l}y=0,185 x+40,31 \\
R^{2}=0,982\end{array}$ & 52,345 \\
\hline 4 & Rimpang & $\begin{array}{l}y=0,168 x+40,09 \\
R^{2}=0,995\end{array}$ & 58,638 \\
\hline 5 & $\begin{array}{l}\text { Vitamin } \\
\mathrm{C}\end{array}$ & $\begin{array}{l}y=3,405 x+37,10 \\
R^{2}=0,986\end{array}$ & 3,787 \\
\hline
\end{tabular}

Uji toksisitas akut pada tiap bagian tanaman Wualae menggunakan metode Brine Shrimp Lethality Test (BSLT). Larva artemia salina yang digunakan adalah yang berumur 48 jam. Hal ini disebabkan setelah berumur 48 jam, larva udang artemia salina sudah dapat mencerna makanan karena mulut dan saluran pencernaannya telah terbentuk sempurna, serta ketahanan tubuhnya telah meningkat [9). Data penelitian sitotoksis akut dianalisis probit menggunakan aplikasi MiniTab 17 for Windows dan hasilnya dapat dilihat pada Tabel 4.
Setelah dilakukan uji toksisitas akut, diperoleh hasil terjadi kematian larva Artemia salina Leach setelah diberikan ekstrak etanol buah, daun, batang, dan rimpang Wualae, sedangkan pada kontrol negatif tidak terjadi kematian larva Artemia salina Leach, hal ini menunjukkan bahwa penggunaan DMSO sebagai pelarut tidak toksik sehingga tidak mempengaruhi nilai LC $_{50}$ ekstrak etanol masing masing bagian tanaman Wualae.

Tabel 3. Nilai $\mathrm{LC}_{50}$ Bagian Tanaman Wualae

\begin{tabular}{|c|c|c|c|c|}
\hline No & Sampel & $\begin{array}{c}\text { Konsentrasi } \\
(\mu \mathrm{g} / \mathrm{mL})\end{array}$ & $\begin{array}{c}\% \\
\text { Mortalitas }\end{array}$ & $\begin{array}{c}\mathbf{L C}_{50} \\
(\mu \mathrm{g} / \mathrm{mL})\end{array}$ \\
\hline \multirow{5}{*}{1.} & \multirow{5}{*}{ Buah } & $500 \mathrm{ppm}$ & 30 & \multirow{5}{*}{1302.31} \\
\hline & & $250 \mathrm{ppm}$ & 26,6 & \\
\hline & & $125 \mathrm{ppm}$ & 23,3 & \\
\hline & & $62,5 \mathrm{ppm}$ & 16,6 & \\
\hline & & $31,25 \mathrm{ppm}$ & 6,6 & \\
\hline \multirow{5}{*}{2.} & \multirow{5}{*}{ Daun } & $500 \mathrm{ppm}$ & 30 & \multirow{5}{*}{1162.84} \\
\hline & & $250 \mathrm{ppm}$ & 26,6 & \\
\hline & & $125 \mathrm{ppm}$ & 23,3 & \\
\hline & & $62,5 \mathrm{ppm}$ & 16,6 & \\
\hline & & $31,25 \mathrm{ppm}$ & 6,6 & \\
\hline \multirow{5}{*}{3.} & \multirow{5}{*}{ Batang } & $500 \mathrm{ppm}$ & 30 & \multirow{5}{*}{1174.52} \\
\hline & & $250 \mathrm{ppm}$ & 26,6 & \\
\hline & & $125 \mathrm{ppm}$ & 23,3 & \\
\hline & & $62,5 \mathrm{ppm}$ & 16,6 & \\
\hline & & $31,25 \mathrm{ppm}$ & 6,6 & \\
\hline \multirow{5}{*}{4.} & \multirow{5}{*}{ Rimpang } & $500 \mathrm{ppm}$ & 36,6 & \multirow{5}{*}{1074.72} \\
\hline & & $250 \mathrm{ppm}$ & 26,6 & \\
\hline & & $125 \mathrm{ppm}$ & 23,3 & \\
\hline & & $62,5 \mathrm{ppm}$ & 26,6 & \\
\hline & & $31,25 \mathrm{ppm}$ & 13,3 & \\
\hline 5. & $\begin{array}{l}\text { Kontrol } \\
\text { negatif }\end{array}$ & 0 & 0 & 0 \\
\hline
\end{tabular}

Nilai $\mathrm{LC}_{50}$ ekstrak buah, daun, batang dan rimpang Wualae $>1000 \mu \mathrm{g} / \mathrm{mL}$, sehingga menurut katagori toksisitas Hinwood [10] masuk katagori sedikit toksik (slightly toxic). Semua bagian tanaman Wualae dapat dijadikan alternatif bahan baku obat herbal yang berkhasiat antioksidan karena daun, buah, batang dan rimpang Wualae memiliki aktivitas sebagai antioksidan kuat, serta nilai $\mathrm{IC}_{50}$ lebih kecil dari nilai $\mathrm{LC}_{50}(<10 \%)$.

\section{Kesimpulan}

Semua bagian tanaman Wualae memiliki aktivitas antioksidan yang kuat. Efektifas antioksidan yang paling baik terdapat pada bagian batang Nilai $\operatorname{IC}_{50}(52,345 \mathrm{mg} / \mathrm{L})$, selanjutnya pada rimpang $(58,638 \mathrm{mg} / \mathrm{L})$, pada buah $72,518 \mathrm{mg} / \mathrm{L}$ dan pada daun $99,890 \mathrm{mg} / \mathrm{L}$, dan semua ekstrak tergolong dalam kategori sedikit toksik (slightly toxic)

\section{Ucapan Terima Kasih}

Penulis menyampaikan terima kasih kepada Kementerian Riset, Teknologi, dan Pendidikan Tinggi RI melalui pendanaan Penelitian Dasar Unggulan Perguruan Tinggi 2017. 


\section{Daftar Pustaka}

1. Handajani A, Roosihermiatie B, Maryani H. Faktor-Faktor yang Berhubungan Dengan Pola Kematian pada Penyakit Degeneratif di Indonesia, Buletin Penelitian Kesehatan, 2010, 13 (1);42-53

2. Badarinath A, Rao K,Chetty CS, Ramkanth S, Rajan T, Gnanaprakash K., 2010, A Review on In-vitro Antioxidant Methods: Comparisons, Correlations, and Considerations. International Journal of Pharm Tech Research, 1276-1285.

3. Ayoola GA, Folawewo AD, Adesegun SA, Abioro OO, Adepoju-Bello AA, Coker HAB. Phytochemical and antioxidant screening of some plants of Apocynaceae from South West Nigeria, African Journal of Plant Science, 2008, 2(9);124-128.

4. Mandal S, Yadav S, Nema R. Antioxidants: a review. $J$ of Chem and Pharm Res, 2009, 1(1);102-104.

5. Maimulyanti A, Prihadi, AR. Chemical composition, phytochemical and antioxidant activity from extract of
Etlingera elatior flower from Indonesia, $J$ of Pharmacog and Phytochem, 2015, 3(6);233-238.

6. Pietta PG. Flavonoids as Antioxidants, J.Nat. Prod., 2000, 63(7);1035-42

7. Molyneux P. The Use of The Stable Free Radical Diphenyl Picrylhydrazil (DPPH) for Estimating Antioxidant Activity. Songklankarin J. Sci.Technol., 2004, 26(2);211-219.

8. Blois MS. 1958. Antioxidant Determinations By The Use of a Stable Free Radical. Nature, 1958, 18(1);1199-1200

9. Reskianingsih. Uji Toksisitas Akut Ekstrak Etanol Buah Paleria macrocarpa (Scheff) Boerl terhadap Larva Artemia salina Leach dengan Metode Brine Shrimp Lethality Test (BSLT), Skripsi, Universitas Islam Negeri Syarif Hidayatullah, 2014.

10. Hinwood. Whats $\mathrm{Is}_{\mathrm{L}} \mathrm{D}_{50}$ and $\mathrm{LC}_{50}$ ?, Canadian centre for occupational Health and Safety, diakses pada 23 Agustus $2018<$ http://www.ccohs.ca/oshanswers/chemicals/LD 50. 